\title{
Aspectos discursivos \\ sobre/no ensino-aprendizagem de língua inglesa \\ e na formação de professores em um curso EaD
}

\author{
Cristiane C. de Paula Brito \\ Universidade Federal de Uberlândia \\ depaulabrito@gmail.com
}

Simone Tiemi Hashiguti

Universidade Federal de Uberlândia

simonehashiguti@gmail.com

\section{Resumo}

Este trabalho visa apresentar resultados parciais de uma investigação sobre o ensino-aprendizagem de língua inglesa (LI) e formação de professores, desenvolvida em um curso de graduação em língua e literatura inglesas, em uma universidade pública mineira. À luz dos pressupostos teóricometodológicos da Análise do Discurso francesa em interface com os estudos em Linguística Aplicada, propomo-nos a discutir: (i) o desenho do curso e materiais e seu possível impacto na formação dos licenciandos; (ii) as representações por eles construídas acerca dos processos de ensinoaprendizagem de LI a distância; e (iii) as práticas de aprendizagem que têm sido desenvolvidas no curso. As análises apontam que a relação dos sujeitos com a LI vai se delineando e se ressignificando ao longo do curso e que as práticas de linguagem desenvolvidas no contexto das novas tecnologias se dão em processos de descontinuidade e não de uma suposta ruptura, trazendo à tona a relação singular que os sujeitos estabelecem com a língua que aprendem-ensinam.

Palavras-chave: $\mathrm{EaD}$, ensino-aprendizagem de língua inglesa, discurso, formação de professores.

\begin{abstract}
This paper presents partial results of a research on the teaching and learning of English language (EL) and teacher education, developed in an undergraduate course in English language and English language literature at a public university in the State of Minas Gerais, Brazil. In light of the theoretical and
\end{abstract}


methodological assumptions of the French Discourse Analysis in its interface with studies in Applied Linguistics, we propose to discuss: (i) the course design and materials and their possible impact on the development of the undergraduates; (ii) the representations of the processes of teaching and learning the EL at a distance as built by them; and (iii) the learning practices that have been developed in the course. The analyzes suggest that the relationship of the subjects with the EL is constituted and given new meanings throughout the course and that the language practices developed in the context of the new technologies happen in discontinuity and not as a possible rupture, revealing the singular relationship that subjects have with the language that they learn-teach.

Keywords: distance education, teaching and learning of English, discourse, teacher education.

\section{Introdução}

Os cursos de educação a distância $(\mathrm{EaD})$ em âmbito universitário configuram-se como uma modalidade relativamente nova no Brasil. Institucionalizada em 2005, a Universidade Aberta do Brasil (UAB) abrange cursos de educação a distância em diferentes áreas do conhecimento e representa uma demanda de ampliação do acesso à educação superior. Contudo, a criação desses cursos se encontra em processo, assim como a cultura de educação a distância está ainda em formação. A relação ensino-aprendizagem nesse contexto tem sido tema de muitos debates, teorias e pesquisas ${ }^{1}$.

Neste trabalho, apresentamos resultados parciais de uma investigação sobre o ensino-aprendizagem de língua inglesa (LI) e formação de professores, desenvolvida em um curso de graduação em língua e literatura inglesas, iniciado em 2011, em uma universidade pública no interior de Minas Gerais. A partir do escopo teórico da Análise do Discurso francesa em interface com os estudos em Linguística Aplicada, propomo-nos a discutir: (i) o desenho do curso e materiais e seu possível impacto na formação dos licenciandos; (ii) as representações por eles construídas acerca dos processos de ensino-

\footnotetext{
${ }^{1}$ A esse respeito ver Arruda (2012), Kenski (2007), Menezes (2001), Soto
} (2009), Tumolo (2006), UNESCO (2011) e Wang e Vásquez (2012). 
aprendizagem de LI a distância; e (iii) as práticas de aprendizagem que têm sido desenvolvidas no curso.

Para dar conta desses objetivos, faremos uma breve explanação sobre alguns aspectos do curso analisado; em seguida, explicitaremos a base teórica-metodológica que fundamenta a pesquisa; passaremos, então, à análise e discussão das representações; e teceremos algumas considerações finais.

\section{Sobre o curso}

O curso de graduação em Letras enfocado nesta pesquisa tem duração de 04 anos e teve início em 2011. Foi implantado para suprir a demanda de formação de professores da educação básica pública ${ }^{2}$ e licencia professores de língua e literaturas de língua inglesa. $\mathrm{O}$ curso funciona nos moldes da Universidade Aberta do Brasil - UAB em quatro polos no Estado de Minas Gerais. Inicialmente, contou com mais de 160 alunos matriculados, tendo esse número diminuído ao longo do tempo, por motivos variados. Os alunos são adultos, de idades entre 18 a 60 anos, à época do início do curso, sendo, na maioria, provenientes de escolas públicas e que não tinham realizado nenhum curso de língua inglesa particular. A experiência com educação formal a distância foi a primeira para todos os alunos.

O curso ocorre na plataforma MOODLE, ambiente virtual de aprendizagem e interação, institucionalizado pela Universidade, e seus materiais - constituídos de guia de estudos com explicações teóricas e exercícios, em formatos digital e impresso, e videoaulas digitais e em DVDs disponibilizados aos alunos - são totalmente produzidos pelos professores participantes. Cada período conta com quatro ou cinco disciplinas, ocorrendo duas ou três por vez, com o acompanhamento dos professores formadores, que também são responsáveis pela realização de webconferências ao longo das disciplinas. O curso funciona no modelo UAB, com um tutor presencial e um a distância

\footnotetext{
${ }^{2}$ Curso implantado por universidade pública em resposta à chamada do Plano Nacional de Formação de Professores da Educação Básica Pública (PARFOR), instituído por meio da Portaria Normativa $n^{\circ}$ 9, de 30 de junho de 2009.
} 
para cada 25 alunos, e de acordo com os parâmetros de design e organização da plataforma MOODLE do Centro de Educação a Distância da Universidade.

Uma das particularidades do curso, e a que mais nos interessa nesta proposta de pesquisa, é o acontecimento dos processos de ensino e aprendizagem de língua inglesa e literaturas de língua inglesa a distância, via Internet e ferramentas digitais. Diferentemente de outros cursos superiores a distância, cujas interações e materiais didáticos podem, de certa forma, prescindir da presença de uma língua estrangeira, o curso ora enfocado visa formar profissionais com proficiência em língua inglesa, com a capacitação em todas as habilidades (escrita, fala, compreensão oral e leitura) de maneira a preparar os alunos para serem professores de excelência na educação básica. A formação em língua inglesa, entretanto, é um desafio, não só pelo contexto da $\mathrm{EaD}$, no qual se encontra o curso, mas também pela nossa história com a língua inglesa e seus processos de ensino formais.

Há, no Brasil, certa descrença e até mesmo resistência com relação à possibilidade de aprendizagem da língua em cursos na educação fundamental e média, em escolas públicas ${ }^{3}$, principalmente, e também nos cursos superiores, seja pelo efeito das campanhas publicitárias das escolas de idiomas, seja pelo efeito de status social que elas conferem àqueles que delas são clientes, seja pelos métodos de ensino e materiais que circularam mais massivamente em nossas escolas nos últimos 40 anos, quando a inserção mais significativa da língua inglesa no país ocorreu, seja pela situação pós-colônia que funda uma relação particular com as línguas impostas nos processos político-econômicos ao longo dos anos. Numerosos são os casos reportados de insucesso na aprendizagem da língua no Brasil em cursos presenciais. Sobre os cursos na modalidade a distância, dados coletados informalmente no curso de Letras ora enfocado (notas, comentários e relatos), utilizados internamente para avaliação dos materiais e atividades produzidos, mostram que a dificuldade de aprendizagem, para alguns, é grande, que a língua estrangeira é uma barreira, bem como, em um primeiro momento, antes de haver uma cultura de aprender a distância, a construção do saber em ambientes e

\footnotetext{
${ }^{3}$ A esse respeito, conferir Lima, 2011.
} 
por via das relações inter-pessoais virtuais pode ser considerada uma barreira, para esses alunos.

Nas disciplinas do curso, entretanto, tem-se explorado a desconstrução de representações equivocadas e cristalizadas no senso comum sobre o que é língua estrangeira e aprender língua estrangeira, a relação com a língua materna em vários de seus aspectos (e.g.: construção de identificações sociais, relação com a construção dos saberes de outras disciplinas, relação com a prática de leitura etc.), objetivando uma formação docente significativa, científica e crítica, conforme proposto em seu Projeto Político Pedagógico.

\section{Escopo teórico-metodológico}

Esta pesquisa se localiza no campo de estudos em Linguística Aplicada com ênfase nos processos de ensino-aprendizagem de línguas estrangeiras e segue uma perspectiva teórico-metodológica discursiva de linguagem (CORACINI, 1995; SERRANI-INFANTE, 1998a; REVUZ, 1998; PÊCHEUX, 1975/1997a; FOUCAULT; 1969/2005), na qual são teorizados os conceitos de sujeito, constituído por e na linguagem e de inconsciente, língua, como materialidade simbólica, estrutura parcialmente autônoma cujas representações imaginárias são afetadas por políticas linguísticas e instituições e sentido, como resultante do encontro do sujeito com uma materialidade simbólica e relacionado aos processos ideológicos e históricos. À luz dos pressupostos teóricos da Análise do Discurso francesa, partimos do conceito de discurso como efeito de sentidos entre interlocutores (PÊCHEUX, 1969/1997b), marcado por sua dimensão de estrutura e acontecimento (PÊCHEUX, 1983/2002) - que tem sentido à medida que se relaciona com outros discursos, com dizeres anteriores. Ademais, compreendemos que os discursos se constituem na/pela exterioridade e historicidade, o que equivale a dizer que são perpassados por dizeres anteriores e são sempre marcados pela alteridade e pela polifonia.

A localização dentro da Linguística Aplicada, compreendida como área de estudos transdisciplinar e híbrida (MOITA LOPES, 2006), que une teorias e métodos de diferentes disciplinas a fim de poder responder às complexidades e dinamicidade de seus temas de 
pesquisa, e dentro da Análise de Discurso, compreendida como disciplina de entremeio (ORLANDI, 2001), que dialoga com várias disciplinas para compreender os funcionamentos discursivos, permite que a questão da aprendizagem de língua inglesa através das tecnologias de informação e comunicação e à distância possa ser adequadamente abordada. Nesse contexto, nosso gesto de interpretação em relação aos dados consiste em analisar materialidades verbais e visuais, sequências visuais e discursivas que possam nos remeter a regularidades enunciativas, isto é, a dizeres que, ainda que diferentes nas diferentes materialidades, evocam vozes e produzem efeitos de sentido semelhantes. Fundamentamo-nos na concepção de representação enquanto formações imaginárias, a saber, como jogo de projeções que os interlocutores fazem de si e do outro (PÊCHEUX, 1969/1997b, p. 82).

Para investigar os três aspectos propostos nesta pesquisa, ou seja, o design dos materiais, as representações de ensino-aprendizagem de LI em circulação no curso, e as práticas de aprendizagem em funcionamento, elegemos: (1) dizeres e relatos de alunos em fóruns voltados para a discussão da produção oral em língua inglesa, no início e penúltimo semestre do curso e (2) respostas a questionários sobre o AVA e os guias de estudo e sobre práticas de aprendizagem de língua inglesa dentro e fora do AVA aplicados ao longo do curso. Sobre (1), a escolha desse recorte se dá pelo fato de que o 'domínio da oralidade' configura-se como sinônimo de aprendizagem de língua estrangeira (LE), havendo, nesse sentido, uma ressonância discursiva entre 'falar a LE' e 'saber a LE' (BRITO \& GUILHERME, 2014). O desejo desse domínio é perpassado pelo imaginário de uma língua ideal (e, portanto, inatingível) e é reforçado, sobretudo, pelo discurso midiático acerca do ensino de línguas estrangeiras (GUILHERME, 2009; GRIGOLETTO, 2010; BRITO, 2012), o qual, por sua vez, incide na relação do sujeito para com a língua que aprende-ensina, gerando, inclusive sentimentos de fracasso.

Já a escolha de (2) se deve à necessidade de verificarmos se o AVA e os guias de estudo, enquanto ambiente e materiais institucionalmente legitimados de ensino e formas de tecnologia com design específicos, podem influenciar na aprendizagem da língua estrangeira e se, a partir da construção de um hábito de aprendizagem a distância, outras práticas autônomas de aprendizagem vêm sendo 
desenvolvidas pelos alunos, e se sim, quais e como. Isto é, propõe-se verificar se uma dificuldade de relação com o AVA ou com os guias de estudos poderia afetar a aprendizagem da língua inglesa, ou seja, se uma dificuldade de tecnologia ou condução das atividades no AVA por motivo do design, fatores externos à língua estrangeira, mas determinantes para o acontecimento do curso, poderia afetar sua aprendizagem, ao mesmo tempo em que observamos se outras práticas de linguagem em outras interfaces digitais também têm ocorrido e favorecido a aprendizagem, alterando as formas tradicionais de ensino de língua inglesa comumente propostas por cursos presenciais.

Por design, entendemos a junção da arte e da tecnologia para a criação de objetos ou espaços funcionais, agradáveis e acessíveis, conforme proposto pelo movimento Bauhaus, iniciado na Alemanha em 1919, pelo arquiteto Walter Gropius e outros profissionais de áreas variadas. Considerada como o movimento que institui a disciplina de design no ocidente, a escola Bauhaus propunha o estudo e combinação de materiais diversos, a simplicidade, a versatilidade e a inovação tecnológica em seus produtos. Esses sentidos são também os que direcionam a produção de materiais didáticos instrucionais, sobretudo, os que são desenvolvidos para serem consumidos na tela do computador, como as temos praticado na contemporaneidade. Além da influência da escola Bauhaus para o conceito de design moderno, a própria forma de aprendizagem por ela proposta indica maneiras de lidar com as tecnologias. O ensino multidisciplinar, baseado na aprendizagem pela prática, observação e análise propunha a formação de profissionais críticos, habilidosos, autônomos e capazes de fazer convergir diferentes materiais e tecnologias para um propósito específico. Essa proposta se assemelha muito à forma como os alunos de um curso EAD devem lidar com os diferentes espaços e ferramentas digitais para empreender seus processos de aprendizagem nesse contexto ${ }^{4}$.

É importante levar em consideração que a metodologia para análise da perspectiva teórica aqui adotada se refere à construção de enunciados de referência que podem ser extraídos da leitura do conjunto de dados e da compreensão dos sentidos regulares, das

${ }^{4}$ Sobre a influência do movimento Bauhaus na educação, conferir Chen e He (2013). 
regularidades enunciativas (FOUCAULT, 1969/2005). Essa regularidade, de certa forma explorada também por Pêcheux (1969/1997b) e retomada por Courtine (1983/2009), diz respeito à repetição de um sentido, ainda que em diferentes formulações, a uma existência interdiscursiva, enunciada por diferentes sujeitos, submetidos a um mesmo regime de verdade. Como o conjunto de dados analisado é composto de respostas a questionários com questões abertas e fechadas e de relatos abertos, há, na análise, um batimento entre o resultado das respostas às questões fechadas, cujos resultados podem ser organizados em porcentagens e itens específicos (ex: quais tipos de atividades são mais apreciadas ou mais difíceis de realizar no AVA), e os relatos, de forma a ser possível tentar compreender de maneira ao mesmo tempo ampla e minuciosa, como os processos de aprendizagem da língua inglesa estão acontecendo no curso: ampla porque, com os itens elencados nas questões fechadas, é possível disponibilizar aos participantes mais aspectos do curso para avaliação e reflexão, aspectos que talvez pudessem ficar esquecidos quando da escrita das respostas às questões abertas ou dos relatos; minuciosa porque, esses itens podem ressoar aspectos que não tenham sido explicitados nas respostas dissertativas e relatos, mas que se refiram às práticas de linguagem/aprendizagem e indiquem quais estão em funcionamento.

\section{Resultados preliminares}

\subsection{O desenho dos materiais e as práticas de aprendizagem}

No terceiro período do curso, os alunos foram convidados a responder a um questionário online, com questões objetivas acerca do curso, dos materiais, da relação com tutores e entre os alunos, havendo duas questões com possibilidade de respostas dissertativas, uma sobre as dificuldades no curso, e uma sobre sugestões. Houve 28 participações, sendo os respondentes 22 mulheres e 6 homens, distribuídos pelos quatro polos. Nas questões que indagavam a relação com o AVA e os guias de estudo, a maioria das respostas indicou que 
(a) O design do AVA e dos guias de estudo é fácil e que a organização é boa

Esse enunciado aponta que não há dificuldades experienciadas pelos alunos com relação à utilização do AVA e ao formato dos guias, excluindo, em um primeiro momento, a possibilidade de que o AVA ou os guias influenciassem de maneira negativa, por seu formato e tipo de tecnologia, na aprendizagem da LI. Algumas das formulações dos participantes da pesquisa que possibilitam a construção desse enunciado são ${ }^{5}$ :

(SD01) Não tenho dificuldades, mas sugiro que as matérias já finalizadas ficassem menos visíveis para que não precisássemos procurar pelas atuais no meio de todas.

(SD02) Nenhuma. As vezes ocorre de não abrir um link, mais sempre que acontece, logo tem solução.

(SD03) Não tenho dificuldades. Às vezes o problema é com a minha internet.

(SD04) Tenho dificuldade de postar as tarefas nos devidos lugares, mas já melhorei muito.

(SD05) No início achei um pouco complicado, pois era uma novidade para mim, mas nada que fosse impossível. Agora já me adaptei e não vejo problemas em utilizar.

(SD06) A exceção de algumas falhas no funcionamento de algumas ferramentas (Chat, etc) não vejo nenhuma grande dificuldade de utilização.

Cabe mencionar que o AVA em questão é o MOODLE em sua versão 1.9 , e conforme características de edição disponibilizadas

${ }^{5}$ Todas as sequências foram transcritas tais quais registradas pelos sujeitos, sem quaisquer correções, uma vez que a materialidade linguística pode apontar, ao leitor, a emergência de efeitos de sentidos não delineados por nós. Ademais, destacamos, em itálico, palavras e expressões, no intuito de melhor explicitar nosso gesto de interpretação em relação aos dizeres. 
dentro do padrão do Centro de Educação a Distância da Universidade. O MOODLE é uma plataforma que funciona como sala de aula virtual, em que ocorrem interações entre os usuários (alunos, tutores, professores, coordenadores) entre si e entre eles e os materiais, ferramentas e atividades da própria plataforma e que são criados e editados pela equipe do curso (ex: fóruns de discussão, sessões de bate-papo, exercícios interativos, envio de arquivos etc.). $\mathrm{O}$ ambiente pode ficar restrito apenas a usuários do curso, que o acessam de qualquer computador com internet. Da versão 1.9 para as do tipo 2.0, já disponíveis, ocorreram mudanças de funcionalidades e customização de layout, com ferramentas de edição, backup e integração com outros sistemas mais fáceis. Seu funcionamento mais ou menos adequado, entretanto, depende mais da compatibilidade com os navegadores do que das versões, pois um fator essencial para seu funcionamento é a forma como cada instituição organiza a plataforma para seus fins.

Pelo mesmo questionário, compreendemos que as atividades mais apreciadas pelos alunos, no AVA, são, em ordem decrescente: fóruns de discussão (86\%), videoaulas $(75 \%)$, gravações de arquivos de áudio (54\%), atividades de compreensão oral (43\%), exercícios de estrutura da língua $(39 \%)$, wikis $(32 \%)$, chats $(25 \%)$ e gravações de vídeo (25\%). A leitura desses dados juntamente com a análise das respostas às questões abertas, entretanto, indica, de nosso ponto de vista, que há algumas questões de design do AVA e dos guias que podem ser revistas, como é o caso de fazer possível, tecnicamente, que o AVA apresente características que sejam mais similares a outras redes que são constantemente acessadas pelos usuários e que instituíram práticas de letramento digital específicas. É o que podemos perceber no fragmento abaixo:

(SD07) Gostaria que [o MOODLE] marcasse as tarefas realizadas. Sempre tenho que passear pelas tarefas, porque fico insegura se já fiz. Acho que poderia melhorar o chat. Ele é muito lento. Gostaria que tivéssemos algo como o skype, por exemplo. Acredito que a interação poderia ser melhor.

Também acho que poderia haver como no Facebook, um aviso mostrando que há mensagem pra gente. Ou que fomos citados num fórum... 
Assim, apesar de avaliarem o AVA e os guias como bem organizados e fáceis de utilização e acompanhamento, houve sugestões dos alunos com relação à criação de ícones e ferramentas que indiquem as tarefas já realizadas e pontuadas, à re-organização das atividades para um funcionamento mais fluido, à criação ou permissão de utilização de uma ferramenta de chat com funcionamento melhor e à edição de links para sites que efetivamente funcionem. Pelas sugestões e colocações dos alunos, nossa conclusão parcial é de que há, para alguns, um desejo de que o AVA se assemelhe mais a espaços como as redes sociais (e.g.: Facebook), pois sua prática de navegação e interação na web tem se construído muito significativamente a partir delas, como ilustra a seguinte sequência:

(SD08) Não vejo dificuldades. Mas poderíamos ter um botão "curtir" para as postagens dos colegas. Sei que parece estranho, mas tem horas que não temos tempo para fazer um comentário por escrito e se tivesse um jeito apenas de avisar ao colega que lemos e gostamos, seria muito bom. i ou qualquer outro símbolo que significasse isso: olha, gostei do que você disse, concordo... ficaria bem versátil e prazeroso.

Pode ser que haja, portanto, um truncamento, neste momento, entre o que se considera ser um espaço adequado à aprendizagem em nível superior, formal e legitimado, e modelos de interação interpessoal em funcionamento na contemporaneidade. Isto é, pode ser que, ao mesmo tempo em que os alunos se relacionam mais e mais em comunidades por eles criadas em redes sociais, o AVA possa ser sentido como rede limitada em suas possibilidades de interação usuário-ambiente e usuário-usuário, mas é ainda o que legitima o curso e o faz ser sentido como curso de graduação de uma universidade.

\subsection{Representações sobre os processos de ensino-aprendizagem de LI a distância: deslocamentos em curso}

Para investigar as representações construídas pelos licenciandos sobre os processos de ensino-aprendizagem de LI a distância, foram analisadas postagens dos alunos em três fóruns de discussão que ocorreram em dois momentos do curso. O primeiro 
fórum foi proposto na disciplina de produção oral em LI, ministrada no $2^{\circ}$. Período, no intuito de encorajar os alunos a avaliarem o curso, expressando suas opiniões, sugestões e posicionamentos acerca dos pontos positivos e negativos, bem como acerca do que aprenderam e das dificuldades que encontraram. Os outros dois, intitulados 'Talking about pronunciation' e 'Varieties in English Pronunciation, aconteceram no sétimo período, por ocasião de uma oficina virtual com foco na compreensão e produção oral em LI. Nosso gesto de leitura se deu no sentido de levantar as regularidades enunciativas dos dizeres e investigar possíveis deslocamentos discursivos acerca dos processos de ensino-aprendizagem de LI.

Vale ressaltar que optamos, nesse momento da pesquisa, por examinar os sentidos que vêm à tona quando o sujeito é interpelado a interagir com colegas e tutores acerca de um determinado tópico ${ }^{6}$. Para tanto, tomamos os fóruns como unidade de sentido, isto é, longe de ser um ambiente 'neutro', em que se depositam informações ou opiniões, entendemos que eles se constituem como espaço em que práticas de linguagem são reconfiguradas, a partir de relações de alteridade. Afirmamos isso, pois é comum, por exemplo, que a linha argumentativa, nos fóruns, seja balizada pelas postagens iniciais e corroborada, então, pelas seguintes. Constrói-se, assim, um efeito de verdade acerca dos temas propostos para discussão, já que, muitas vezes, não há vozes outras que venham desestabilizar ou questionar as posições primeiras, mas sim, a repetição de sentidos, em processos parafrásticos. Nessas condições, o fórum pode se tornar um espaço monofônico, em que conflitos e tensões são apagados, especialmente se não há uma efetiva intervenção dos tutores, assumindo o papel de interlocutores dos professores em formação.

As discursividades construídas em um fórum de caráter acadêmico-institucional são determinadas por aspectos, tais como: o jogo de formações imaginárias (PÊCHEUX, 1969/1997b); as orientações pedagógicas dadas para a execução da atividade; enfim,

${ }^{6}$ Em outro momento, cabe-nos investigar os deslocamentos discursivos empreendidos pelo mesmo sujeito, ao longo do curso, a fim de compreender sua inscrição e movimentos de identificação com certas discursividades e contemplar os processos de ensino-aprendizagem por um viés que considere a singularidade. 
por interdições e injunções que, mais ou menos explicitamente, vão delineando os dizeres e incindindo naquilo que pode e deve ser dito no ambiente virtual. E, nesse sentido, lançar olhares ao funcionamento discursivo de fóruns acadêmicos pode nos auxiliar na compreensão dos processos interacionais em contexto de ensino a distância. Tendo esclarecido isso, passamos à discussão dos resultados.

Nas postagens analisadas no fórum do segundo período, um discurso recorrente foi o da dificuldade de aprendizagem de LI a distância, sustentado pela representação de que não se aprende LI a distância com a mesma 'eficiência' com que se aprende no presencial. Essa representação pode ser sintetizada pelo enunciado:

\section{(b) É difícil desenvolver a oralidade em inglês sem encontros presenciais.}

Nesse momento do curso, foi frequente a queixa, entre os alunos, de que sem aulas presenciais, sem a interação face a face, o desenvolvimento da produção oral fica muito prejudicado, especialmente para aqueles que são iniciantes. Atribui-se, assim, à 'distância' o insucesso (ou o maior insucesso) da aprendizagem da língua inglesa, o que parece agravar a percepção da falta e das dificuldades inerentes à própria complexidade da aprendizagem, como se vê nas seguintes sequências:

(SD09) Acho impossível adquirir uma oralidade razoável, sem um trabalho de conversação com um tutor ou professor especialmente dirigido à essa grande dificuldade. $(2 \mathrm{P})^{7}$

(SD10) Há um plano de se colocar um tutor no polo aqui para trabalhar conosco. Vamos aguardar né???? Só sei que é preciso com urgência algo que nos faça deslanchar quanto a pronúncia, pois ai estaremos conseguindo ouvir, entender, falar e escrever. (2P)

\footnotetext{
${ }^{7} 2 \mathrm{P} \mathrm{e} 7 \mathrm{P}$ serão utilizados para se referir às postagens solicitadas nos fóruns do segundo e sétimo períodos do curso, respectivamente.
} 
Ao enunciar sobre o não domínio da oralidade, é interessante notar os sentidos de completude atribuídos à pronúncia, como se seu domínio implicasse - automaticamente - a capacidade de compreensão oral e escrita na língua. Ademais, vê-se que o sujeito se coloca em uma atitude passiva em relação à aprendizagem, projetando o conhecimento como produto externo, fora dele e passível de ser 'ativado' por algo exterior, algo que o fizesse deslanchar.

O discurso da dificuldade de aprendizagem de LI a distância é respaldado pelo discurso da falta, o qual, por sua vez, se sustenta, interdiscursivamente, pela memória da normatividade, em que 'saber língua' é 'saber corretamente':

(SD11) Fico me vendo numa sala de aula, com um punhado de adolescentes rindo dos meus erros de compreensão e produção oral. (2P)

Ao projetar o olhar de um outro na enunciação - um punhado de adolescentes - o sujeito convida o interlocutor a também olhar na mesma direção, de modo a contemplar esse riso que cai (ou cairá) sobre ele quando estiver à frente de uma sala de aula cometendo erros de compreensão e produção oral. No entanto, mais que um convite, os dizeres parecem assumir o caráter de uma injunção (quase uma atribuiçao de culpa) no sentido de interpelar o outro a tomar uma atitude acerca dos supostos erros mencionados, o que pode ser corroborado pela sequência abaixo, escrita pelo mesmo sujeito:

(SD12) [...] não somos formados em inglês, a grande maioria é de demanda social, [vocês] já deveriam ter pensado numa maneira razoavel de nos ensinar produção oral e compreensão, concretamente. (2P)

Vê-se que essa sequência, enunciada nos primeiros períodos do curso, e quando do primeiro embate do sujeito com a LE, ressoa os dizeres de que o curso seria bom para os que já possuem conhecimento. Aqui o discurso da falta marca um embate com a instituição, se assim podemos dizer, e se marca na queixa de que o curso não apresenta uma maneira razoável de ensinar a produção e 
compreensão oral. Apropria-se da posição-sujeito 'aluno de demanda social', a fim de construir uma 'identidade faltante' perante o interlocutor e assim legitimar suas reinvindicações, ao mesmo tempo em que se resiste (pelo fato mesmo de reinvindicar) à falta que o constitui na relação com a língua e à imagem que faz dela, enquanto professor em formação. É também significativo o uso do advérbio concretamente, o qual parece funcionar dialogicamente com o caráter de EaD do curso. No fio do dizer, concretamente corrobora o sentido da expressão maneira razoável, contrapondo-se, pois a uma outra maneira, que seria 'deficiente', 'faltante'.

No Fórum 'Variations in English Pronunciation', aberto no sétimo período, os alunos deveriam comparar suas pronúncias de diversas palavras com variedades de inglês faladas em diferentes lugares (disponibilizadas em um vídeo). Após fazer a atividade de comparação, solicitou-se que eles se posicionassem acerca de sua pronúncia, de uma possível noção de 'erro', da questão de identificação com certas variedades etc. Chamou-nos a atenção a emergência de dizeres que, de alguma forma, desestabilizam o discurso da normatividade, apontando, a nosso ver, deslocamentos na concepção de 'saber LI'.

(SD13) Muito bom esse vídeo, ele aumenta a minha auto estima no quesito pronuncia. Isso porque nos mostra que a variedade de pronuncia em língua inglesa é semelhante a variedade das nossas regiões. (7P)

(SD14) Fiz essa tarefa com muita insegurança, então, quando comparei minha gravação com o vídeo que surpresa... O termo errar para minha pronúncia era bem aceito antes de realizar essa atividade, mas agora percebo quantas variáveis existem e passo a me considerar num patamar de aprendizagem um pouco mais elevado que antes. (7P)

(SD15) Sobre a questão dos "erros de pronúncia", hoje, após os estudos que já fizemos no decorrer do curso, eu entendo que a abordagem deveria ser outra: não se deveria analisar "erros", mas sim "variações". (7P) 
Não se trata de dizer que houve mudança no sentido de inscrição em uma nova discursividade, mas a interpelação por uma discursividade outra, colocando o sujeito no embate entre um imaginário de completude em relação à língua e suas possibilidades inúmeras de realização, configuradas nos diversos contextos de interação verbal a partir da singularidade dos sujeitos falantes.

Tal discursividade pode funcionar de modo a inscrever $o$ sujeito professor em formação em uma relação com a LI que contemple a produção de linguagem como processo constitutivamente tenso e conflitivo - pela própria natureza da linguagem em si, o que abre espaço para que se trabalhe, no ensino-aprendizagem, a heterogeneidade, o equívoco, a contradição, enfim, a língua(gem) em sua condição de estrutura e o acontecimento.

Cumpre salientar que uma sugestão dada pelos alunos, ao evidenciarem a dificuldade que enfrentam para compreender e produzir em língua inglesa, é a produção de vídeos explicativos (em especial sobre gramática e pronúncia) pelos professores. A videoaula parece, pois, ocupar o lugar do professor - suposta presença que viria suprir a lacuna da interação face a face e 'fornecer' ao aluno o conhecimento. $\mathrm{E}$, nesse sentido, podemos dizer que há um embate de representações acerca da aprendizagem de LI a distancia: de um lado, a representação de sujeito autônomo, tão propagada pelo discurso pedagógico da EaD (TRIFANOVAS, 2011), e corroborada pelo próprio design dos materiais; de outro, a representação de aprendizagem do sujeito aluno, perpassada por suas experiências e imaginário acerca dos processos de ensino-aprendizagem. A videoaula figuraria, assim, como lugar de controle (do conhecimento pelo professor) e de segurança para o aluno.

Funcionando dialogicamente com o discurso da dificuldade, nota-se o discurso da perseverança, o qual marca o movimento de resistência do sujeito frente à percepção da falta em relação à LI. Tal discurso pode ser expresso pelo enunciado (c), abaixo que, contrariamente ao enunciado (b), aponta para a representação de que é possível aprender LI no curso a distância:

(c) Apesar de todas as dificuldades, não desistirei do curso

O curso é descrito como um 'desafio' e os sujeitos relatam a necessidade de se ter determinação, força de vontade, persistência, 
enfim, de lutar e não desanimar, a fim de concluir a graduação em Letras. Apesar das dificuldades que (d)enunciam, eles ressaltam seu desenvolvimento como alunos, bem como a qualidade do curso e do material e o preparo dos profissionais envolvidos, como se observa na seguinte sequência:

(SD16) Eu no curso estou aprendendo gradativamente, tenho visto uma boa evolução, gosto de ver e ouvir os videos com os professores do curso falar e as atividades de repetir as falas. Os textos são interessantes e profundos e nos levam a querer aprender mais o Inglês. (2P)

(SD17) A minha dificuldade no curso é o meu Inglês mais isso agente corre atrás. (2P)

Muito significativa, para nós, é a sequência abaixo, enunciada pelo mesmo aluno que produziu a SD09. Na SD18, ele responde a uma intervenção da tutora, que lhe havia sugerido fazer um curso presencial de inglês em instituto de idiomas:

(SD18) não vou entrar numa escola de idiomas não, vou sair desse curso formada e com conhecimento para transmitir. (2P)

O embate com a tutora, marcado no uso enfático do advérbio não, deixa-nos entrever o desejo do licenciando de se apropriar subjetivamente do lugar que ocupa, isto é, de ser/tornar sujeito aprendente/ensinante de LI por meio do curso EaD. Nesse sentido, ele resiste aos dizeres de uma memória discursiva sobre o ensino de língua inglesa no Brasil que atribui seu sucesso justamente aos institutos particulares, desautorizando outros ambientes - escola regular e universidade - como lugares de aprendizagem. Aliás, se a escola regular (especialmente a pública) e os próprios cursos presenciais de Letras são concebidos como não-lugares de aprendizagem da LI (BRITO \& GUILHERME, 2014), pode-se dizer que, ao reivindicar a legitimidade desse curso, o licenciando instaura uma tensão na relação saber-poder que desestabiliza sentidos naturalizados sobre o ensinoaprendizagem de LI.

Cumpre ainda ressaltar que, ao se inscreverem no discurso da perseverança, os sujeitos destacam a importância do curso para seu 
desenvolvimento pessoal e profissional, apontando a relevância do programa em termos de inclusão social, no cenário do ensino superior no Brasil. Sair desse curso (e não de outro) formada e com conhecimento para transmitir (e não apenas com um diploma) traz à baila o imaginário que os cursos $\mathrm{EaD}$ ocupam em nosso contexto educacional: se por um lado celebram-se as novas tecnologias como ferramentas imprescindíveis para o ensino-aprendizagem, ressaltando seus benefícios e vantagens; por outro, vê-se que os cursos a distância parecem ocupar um lugar à margem (do que se considera 'sério', 'científico', 'legítimo') nas práticas discursivas e sociais da academia.

No Fórum 'Talking about pronunciation', no sétimo período, os alunos foram solicitados a discutir suas percepções acerca dos sons da LI e de seu desenvolvimento e dificuldades na língua, no que concerne à oralidade. Os dizeres corroboram a inscrição dos sujeitos no discurso da perseverança, o qual delineia sentidos de 'progresso' na relação com a língua, como se pode observar nas sequências:

(SD19) Eu tenho bastante dificuldade em quase todos as pronuncias da língua inglesa, principalmente aquelas que são pouco compatíveis com a língua, porém, desde o começo desta faculdade até agora senti uma grande evolução não só no meu conhecimento e interpretação, mas, principalmente nas minhas pronuncias. (7P)

(SD20) Acredito que o mais importante nessa caminhada é percebermos o quanto temos evoluído, mesmo que saibamos o quanto ainda teremos que crescer. (7P)

(SD21) Surely from the beginning of our course until today, I could see a gain in the overall level of my English. Certainly there is much to improve and learning is a lifelong process, but in fact, from the moment we started this graduation, I could see this improvement in myself. (7P)

Nosso gesto de leitura para esses dizeres não se configura como tentativa de reiterar o suposto desenvolvimento dos alunos na LI, já que para isso seria necessária a investigação da enunciação, propriamente dita, na língua alvo, o que foge ao escopo desse estudo. $\mathrm{O}$ que nos interessa é compreender como as sequências trazem à baila 
a relação dos sujeitos com a LI, isto é, como o encontro-confronto com essa língua vai se delineando e se ressignificando ao longo do curso.

\subsection{As práticas de aprendizagem em funcionamento no curso}

Diante da dificuldade de produção oral em língua inglesa, enfrentada por alguns alunos do curso, houve a iniciativa, em 2013, de abertura de um Laboratório de Língua Inglesa Virtual, na qualidade de projeto de extensão, no qual os alunos realizam atividades preparatórias de estudo sobre temas gerais de conversação, a fim de realizarem webconferências em língua inglesa com monitores. Além das atividades de pré-webconferência, em que vocabulário, estruturas linguísticas e expressões em língua inglesa são disponibilizados aos alunos, e webconferência, em que há contato face a face individual com um monitor fluente em língua inglesa por um comunicador online, há também atividades pós-webconferências, que visam fixar as estruturas abordadas e dar dicas de continuidade de estudo sobre os temas. No projeto, os alunos são convidados a participar, e os monitores são orientados a realizar interações que visem à conversação livre sobre os temas. Os alunos que participam do Laboratório foram convidados a responder questionários sobre sua participação no Laboratório e no curso, sobre sua autoavaliação como falante e aprendiz da língua inglesa e sobre suas práticas de aprendizagem individuais. Abaixo, os enunciados de referência extraídos da análise de suas respostas e que representam o que consideram ser necessário para aprender a falar língua inglesa e as práticas de aprendizagem em funcionamento:

(d) aprendemos a falar inglês conversando;

(e) aprendemos a falar ouvindo nativos da língua falando;

(f) dicionários online, redes sociais, outras plataformas de ensino de inglês institucionalizadas, música e filmes são as tecnologias mais utilizadas nas práticas de estudo extra sala de aula. 


\section{Considerações finais}

O presente trabalho apresentou resultados preliminares de uma pesquisa em andamento sobre aprendizagem de inglês em um curso de graduação totalmente a distância. As conclusões parciais a que chegamos, neste momento, indicam que as representações acerca da aprendizagem de língua inglesa e a capacidade de produção oral na língua são perpassadas por imagens e vozes conflitantes, mobilizadas por diferentes posições-sujeito.

Nos dizeres dos professores em formação, essas representações se relacionam com interações face a face, sobretudo presenciais, e a um ideal de falante nativo na língua, tanto como modelo de oralidade, quanto modelo de fonte de material de áudio, não sendo tão influente a dificuldade de utilização de tecnologias de informação e comunicação, conforme hipotetizado no início. Todavia, pudemos observar que elas vão sendo ressignificadas, a partir da inscrição em discursividades que intentam desconstruir sentidos cristalizados da língua e de aprendizagem da língua. Defendemos que as representações se dão em meio a embates, pois, ao enunciar sobre a língua que ensina-aprende, o sujeito toma uma posição discursiva relacionada a práticas de linguagem fora da academia, atrelando a representação de produção oral a práticas cotidianas informais de interrelação pessoal (em redes sociais, a partir de filmes e séries de TV etc) e não à situação de enuciação no contexto acadêmico. Por outro lado, ao evocar o discurso da variação linguística e refutar noções de erro (sobretudo no que diz respeito à pronúncia em LI), assume-se a posição de sujeito professor em formação, que, por sua vez, traz à baila as discussões acadêmicas, de formação em Letras, que têm ocorrido no curso.

Ademais, esses dizeres apontam para a complexidade dos processos de aprendizagem de uma língua estrangeira e, mais especificamente, para o fato de que eles não ocorrem, por exemplo, na mesma velocidade que as inovações tecnológicas. Isto é, ainda que se celebrem os infinitos recursos e vantagens oferecidos pelas ferramentas virtuais (tais como a possibilidade de maior interação e colaboração, o acesso a amostras autênticas de língua, o desenvolvimento da autonomia, o aumento da motivação etc) e que cursos de língua a distância venham trazer formas outras de se ensinar-aprender uma língua, há questões que fogem à relação sujeito-máquina e se 
constituem na relação que o sujeito pode empreender com o(s) outro(s)/Outro. Relação esta que extrapola a transmissão de conteúdos estanques ou o acesso a uma 'explosão de informação' (HUANG et al, 2013).

As representações, ao mesmo tempo em que apontam para o desafio a ser enfrentado pela EaD de ressignificar paradigmas, também indicam que as práticas de linguagem desenvolvidas no contexto das novas tecnologias se dão em processos de descontinuidade e não de uma suposta ruptura. O que está em jogo, mais do que meras questões metodológicas e de design de materiais, é a relação singular que os sujeitos estabelecem com a língua que aprendem-ensinam. Para muitos sujeitos, alunos do curso, o encontro-confronto se dá não apenas com uma nova língua (REVUZ, 1998), mas com uma forma outra de aprender, por meio da inserção em práticas de letramento antes não familiares.

Dizer que os processos de aprendizagem mediados por NTICs provocaram uma reformulação nos papeis atribuídos ao professor e ao aluno parece ser lugar-comum na literatura. Afirma-se que o paradigma tradicional, que colocava o professor como centro do saber e o aluno como receptáculo de conhecimento, não pode mais ser sustentado haja vista que as inovações tecnológicas trouxeram deslocamentos na forma pela qual se concebe o conhecimento. Concordamos que as NTICs sejam mais do que simples ferramentas ou 'acessórios' a serem acrescentados nos processos educacionais e que seu advento veio instaurar relações de natureza diferentes, estabelecendo o que se pode chamar de uma cultura digital ou uma 'tecnologia discursiva', a saber um conjunto de processos em que a produção linguageira e discursiva está imbricada às ferramentas tecnológicas (PAVEAU, 2013).

Contudo, também entendemos que é preciso cautela para que se vejam os processos de ensino-aprendizagem mediados por tecnologias não como a inauguração de uma 'nova' ordem, e sim de uma ordem outra, permeada por práticas e discursos que se imbricam, dialogam e se confrontam. Desse modo, não se trata de conceber esses processos pelo viés de dicotomias sustentadas em noções de 'velho' $\mathrm{x}$ 'novo', 'tradicional' x 'moderno', 'analógico' x 'digital', mesmo porque a refutação de um modelo mecanicista de educação antecede o 
advento do que hoje se denomina NTICs ${ }^{8}$. Como aponta Coracini (2011), as novas tecnologias provocam mudanças, e, ainda que entrecruzadas com o velho, "camuflando o já-visto-ouvido-dito", incidem na subjetividade dos alunos e professores, "na medida em que os colocam sozinhos diante de uma tela, reforçando a solidão e a redução, ou mesmo a ausência, de laços sociais que caracterizam a sociedade de consumo nos tempos (pós-)modernos, guiados pela ideologia neoliberal" (p. 42).

Em outras palavras, trata-se da necessidade de compreensão dos processos de ensino-aprendizagem de LEs mediados por tecnologias, sob perspectivas que extrapolem concepções meramente instrumentalistas, com foco apenas no 'uso' das ferramentas digitais, a fim de se considerarem esses processos pelas vias dos modos de subjetivação, os quais permitem contemplar a relação sujeitolinguagem-ciberespaço (DIAS, 2004)

Trata-se, pois, de compreender como os cursos em EaD têm se desenvolvido, a partir da interdependência dos inúmeros fatores que os constituem, com vistas a elaborar uma 'epistemologia digital da aprendizagem', capaz de formular um quadro teórico-metodológico que fundamente e investigue os processos - sempre heterogêneos que se efetivam no ambiente virtual. No caso do ensino-aprendizagem de línguas, a elaboração dessa epistemologia está fundamentalmente atrelada à concepção do que, afinal, seja 'aprender língua' (WHITE, 2003).

Parece-nos que tal epistemologia terá que levar em conta, sobretudo, o papel da memória. Seja o imbricamento de memórias discursivas que respaldam as representações dos sujeitos acerca do que venha a ser ensino-aprendizagem de LE; interação em contexto virtual; interação em ambientes digitais acadêmicos, dentre outras. Seja a memória afetada pela historicidade que constitui os processos de ensinar-aprender língua inglesa, no contexto brasileiro, permitindo aos sujeitos se engajarem em movimentos de resistência, na e pela linguagem, de forma a confrontar representações de uma língua

${ }^{8}$ A Escola Nova, por exemplo, que surgiu no fim do século XIX, liderada por John Dewey, na América, postulava a necessidade de se articular a aprendizagem à vida e de desenvolver a autonomia do aluno, pautando-se nos princípios da iniciativa, originalidade e cooepração (GADOTTI, 1999). 
idealizada - e, portanto, inatingível - que, ao abafar os conflitos e tensões constitutivos do lugar de sujeito falante, os impedem de se legitimarem como enunciadores de uma língua estrangeira.

\section{Referencias}

ARRUDA, E. P. Educação a distância no Brasil: a pedagogia em foco. Uberlândia: EDUFU, 2012.

BRITO, C. C. P. No embromation... língua inglesa, imagens e mídia. Entremeios: revista de estudos do discurso, 4. Disponível em http://entremeios.inf.br/published/23.pdf. Acesso em 02/10/2012. Acesso em 02/2012.

BRITO, C. C. P. \& GUILHERME, M. F. F. Memorial de aprendizagem e a formação do professor: vozes constitutivas da relação aprender/ensinar línguas estrangeiras. Revista Brasileira de Linguística Aplicada, Vol.14, n. 3, p.511-532, 2014.

CHEN, W. \& HE, Z. The Analysis of the Influence and Inspiration of the Bauhaus on Contemporary Design and Education. Engineering, 5, 2013 Disponível em http://dx.doi.org/10.4236/eng.2013.54044. Acesso em $02 / 2014$.

CORACINI, M. J. R. F. (Org.). O jogo discursivo na aula de leitura: língua materna e língua estrangeira. Campinas: Pontes, 1995.

. Os blogs escolares e a escrita de si: entre a redação escolar e os diários virtuais. In: CORACINI, M. J.; UYENO, E. Y.; MASCIA, M. A. A. Da letra ao píxel e do píxel à letra: uma análise discursiva do e sobre o virtual: identidade, leitura e escrita, formação de professores e ensino-aprendizagem de língua. Campinas: Mercado de Letras, 2011. p. $27-46$.

COURTINE, J. J. [1983] Análise do discurso político: o discurso comunista endereçado aos cristões. Trad. C. C. Birk et al. São Carlos: Edufscar, 2009. 
Aspectos discursivos sobre/no ensino-aprendizagem...

DIAS, C. P. A discursividade da rede (de sentidos): a sala de bate-papo HIV. 2004. Tese (Doutorado em Linguística Aplicada) - Instituto de Estudos da Linguagem, Universidade Estadual de Campinas, Campinas, 2004.

FOUCAULT, M. [1969]. A Arqueologia do Saber. Rio de Janeiro: Forense Universitária, 2005.

GADOTTI, M. História das Idéias Pedagógicas. 7. ed. São Paulo: Ática, 1999.

GRIGOLETTO, M. Língua estrangeira e identidade: discursos sobre as línguas, processos subjetivos e efeitos de fronteira. Entremeios: revista de estudos do discurso, 1 (1), 2010. Disponível em http://www.entremeios.inf.br/published/8.pdf. Acesso 04/2014.

GUILHERME, M. F. F. A construção da subjetividade do graduando em Letras em enunciação institucional sobre competência oral em língua inglesa. In: SANTOS, J. B. C. (Org.). Sujeito e subjetividade: discursividades contemporâneas. Uberlândia: EDUFU, 2009. p. 135156.

HUANG, R. et al. The New Shape of Learning: Adapting to Social Changes in the Information Society. In: HUANG, R.; KINSHUK; SPECTOR, J. M. (Eds.). Reshaping Learning: Frontiers of Learning Technology in a Global Context. Nova York: Springer, 2013. p. 3-42.

KENSKI, V. Educação e Tecnologias: o novo ritmo da educação. Campinas: Papirus, 2007.

LEVY, M. Technologies in Use for Second Language Learning. The Modern Language Journal, 93 (Focus), p. 769-782, 2009.

MENEZES, V. P. (Org.). Interação e aprendizagem em ambiente virtual. Série Estudos Linguísticos. Belo Horizonte: Faculdade de Letras, UFMG, 2001. 
MOITA LOPES, L. P. (Org.). Por uma linguística aplicada indisciplinar. São Paulo: Parábola, 2006.

ORLANDI, E. P. Análise de Discurso: Princípios e Procedimentos. Campinas, SP: Pontes, 2001.

PAVEAU, M.-A. Technodiscursivités natives sur Twitter. Une écologie du discours numérique. In: LIÉNARD, F. Culture, identity and digital writing, Epistémè 9, Revue Internationale de Sciences Humaines et Sociales Appliquées, p. 139-176, 2013.

PÊCHEUX, M. [1969]. Análise Automática do Discurso (AAD-69). In: F. Gadet \& T. Hak (Orgs.). Por uma Análise Automática do Discurso: uma introdução à obra de Michel Pêcheux. Trad. Eni Orlandi. Campinas: Unicamp, 1997b. p. 61-151.

. [1975]. Semântica e Discurso: uma crítica à afirmação do óbvio. Trad. Eni Orlandi. Campinas: Ed. da UNICAMP, 1997a.

. [1983]. O Discurso: estrutura ou acontecimento. 3. ed. Trad. Eni Orlandi. Campinas: Pontes, 2002.

REVUZ, C. A língua estrangeira entre o desejo de um outro lugar e o risco do exílio. In: SIGNORINI, I. (Org.). Língua(gem) e identidade. São Paulo: Mercado de Letras, 1998. p. 213-230.

SERRANI-INFANTE, S. (Org.). Identidade e segundas línguas: as identificações no discurso. Língua(gem) e identidade: elementos para uma discussão no campo aplicado. Campinas: FAPESP/FAEPUNICAMP/Mercado de Letras, 1998a. p. 231-266.

Abordagem transdisciplinar da enunciação em segunda língua: a proposta AREDA. In: SIGNORINI. I. \& CAVALCANTI, M. C. (Orgs.). Lingüística Aplicada e Transdisciplinaridade. Campinas: Mercado das Letras, 1998b. p. 143-167.

SOTO et al. Novas tecnologias em sala de aula. São Carlos: Editora Claraluz, 2009.

TRIFANOVAS, T. R. A discursivização do perfil de autonomia do aprendiz de EaD como forma de homogeneização das subjetividades. 
Aspectos discursivos sobre/no ensino-aprendizagem...

In: CORACINI, M. J.; UYENO, E. Y. \& MASCIA, M. A. A. (Orgs.). Da letra ao píxel e do píxel à letra: uma análise discursiva do e sobre o virtual: identidade, leitura e escrita, formação de professores e ensinoaprendizagem de língua. Campinas: Mercado de Letras, 2011. p. 285315.

TUMOLO, C. H. S. Ensino a distância: horizontes para o ensino de línguas estrangeiras. Fragmentos, 30, p. 25-34, 2006.

UNESCO; Microsoft. Unesco ICT competency framework for teachers. Paris: United Nations Educational, Scientific and Cultural Organization, 2011.

WANG, S.; VASQUÉZ, C. Web 2.0 and second language learning: what does the research tell us? Calico Journal, 29 (3), p. 412-430, 2012.

WHITE, C. Language Learning in Distance Education. Cambridge:

Cambridge University Press, 2003.

Submetido em: 10/09/2014 Aceito em: 24/02/2015

Title: Discursive aspects about/in English teaching-learning and teacher education in a distance course 